\title{
The role of gravitational cues in the judgment of visual orientation*
}

\author{
W. B. TEMPLETON \\ York University, Toronto, Ontario, Canada
}

\begin{abstract}
It is argued that, contrary to the views of some theorists, the role of gravitational cues is essentially one of maintaining orientation constancy. In support of this claim, it is shown that the loss of relevant gravitational information when the body is supine results in a significant increase in the disorienting effects of both a tilted visual frame and tilt of the head relative to the trunk.
\end{abstract}

Head or body tilt is well known to induce constant errors in the judgment of the visual vertical or horizontal. The subjective vertical or horizontal is displaced either in the direction of postural tilt (the $\mathrm{A}$ effect) or in the opposite direction (the E effect). The A effect appears as an underconstancy or failure to take full account of the degree of postural tilt, while the $\mathrm{E}$ effect reflects overconstancy (Day \& Wade, 1969). There is disagreement about the conditions under which the two effects occur, but Miller, Fregly, van den Brink, and Graybiel's (1965) work suggests the $E$ effect as characteristic of small degrees of body tilt (up to 60 or $80 \mathrm{deg}$ ) and the $\mathbf{A}$ effect at greater angles of tilt. Consequently, tilting of the head alone would be expected to produce only the $\mathrm{E}$ effect, since the degree of possible tilt is relatively small (Day \& Wade, 1966).

Early observations by Wertheimer (1912) and Kleint (1936) demonstrated that the visual vertical can also be strongly influenced by the orientation of a visual frame. There has been a great deal of controversy over the causes and the relative importance of these effects (Howard \& Templeton, 1966).

It seems, in general, that labyrinthine defects do not markedly affect postural abilities, at least after an initial period of adaptation to the damage (Thetford \& Guedry, 1952a, b; Clark \& Graybiel, 1963). Similarly, Wing (1963) was unable to record any consistent changes in nerve potentials in the mammalian vestibular ganglion in response to head tilt and suggested that the utricle was largely vestigial in higher mammals, where vision and kinesthesis are dominant in posture control. Both $\mathrm{A}$ and $E$ effects have been recorded in congenitally deaf Ss and Ss with unilateral or bilateral vestibular loss (Feilchenfeld, 1903; Barany, 1921; Fischer, 1930). These results have generally been interpreted as further evidence of the unimportance of vestibular function.

Many of those who have believed that vestibular inputs are important have assumed that when the head or body is tilted, the vestibular input is subject to some special error, which indirectly results in false judgments of visual direction. This assumption was made explicit

\footnotetext{
*This research was supported by National Research Council Grant APA 299.
}

by Witkin and Asch (1948) when they explained their finding that the frame effect was greater when the body was tilted, by suggesting that postural cues are most valid when the body is erect.

It would surely be reasonable to assume that if there is vestibular involvement in judgments of visual direction, it should provide additional information about the orientation of the head and thereby reduce errors due to other postural factors-the A and E effects-and other errors as well, such as the visual-frame effect. There seems to be a tendency for more recent workers to adopt this point of view. Miller and Graybiel (1966) tested normal and labyrinthine-defective Ss on setting a target to horizontal either sitting upright, lying on their sides, or with their heads inverted, and with or without a visible background of objects giving strong veridical cues to vertical and horizontal. All of these postures allow potential utricular information about the direction of gravity. Not surprisingly, both groups were extremely accurate in all postures, provided the visual background was present. In the head-inverted condition, both groups showed a small, but similar, decrement when the visual background was removed; but it is difficult to base any conclusion on this condition, since there is considerable uncertainty about otolithic function in such a posture. In the recumbent position, loss of visual background produced a marked decrement (16 deg of average absolute deviation) in the normals, but a very much larger one (28 deg) in the labyrinthine-defectives. (According to the authors, these figures are a measure of the A effect, since in this posture all the deviations were in the same direction.) Finally, in the upright posture, loss of visual background produced a small, but significant, decrement, but only for the labyrinthine-defectives. Similar results were found in a second experiment, in which the same groups in the same postures had to maintain the target apparently horizontal throughout successive periods when the visual background was either present or absent; the fluctuations during the dark periods were termed "rotary autokinesis." Miller and Graybiel conclude that their evidence contradicts any claim that the utricles operate to produce error in localization associated with head (body) tilt. 
Clark and Graybiel (1968), on the other hand, failed to find any consistent effect of several combinations of head and body tilt on the visual vertical in either normal or defective Ss; constant errors were small throughout. They concluded that the vestibular information was unnecessary for accurate performance. This study was unusual in that, instead of being forced passively into position, the Ss actively and without external support produced and maintained head tilt and body tilt, which were merely monitored by $\mathrm{E}$. The resulting increase in motor-kinesthetic and tactile information may have been sufficient to permit accurate performance with or without the vestibular system.

Another method of eliminating gravitational cues is to have the $\mathrm{S}$ lie supine (or prone) so that the direction of gravity is orthogonal to the plane of rotation of the horizontal line which the $S$ attempts to align with the long axis of $h$ is body. Unlike the use of labyrinthine-defective $S s$, this procedure renders inoperative or irrelevant not only the utricles, but also the complex of tactile-kinesthetic cues to the direction of gravity.

Rock (1954) had his Ss set a line parallel with or at right angles to the long axis of the head when supine. Constant errors were in both directions and ranged up to $9 \mathrm{deg}$, and standard deviations ranged from 2 to $6.5 \mathrm{deg}$, with a mean of $4 \mathrm{deg}$. Rock judged this an accurate performance and concluded that the loss of gravitational cues was not serious. This appears to be totally unwarranted. The task is a relatively simple one, involving only two links (the orientation of the line on the retina and of the eye in the head); in any case, it is not known how accurate performance is in the erect posture and no control group was used.

The supine posture was also used by Brosgole and Cristal (1967) in a recent attack on the now almost universal view that visual and postural cues interact to determine the visual vertical, that, for example, a tilted frame in conflict with the postural cues of an erect $O$ produces a compromise change in felt orientation, which in turn gives rise to a modified conception of visual space. They point out that there is here an implicit assumption that the visual vertical is directly determined by the felt orientation of the body, and yet it is precisely this link which has never been studied-how gravity, which gives information only about the orientation of the body, can be used in the judgment of the orientation of a target which is sensed only visually. In addition, the interactionist view would seem to require a similar size change in apparent body orientation, whereas Passey (1950) found that the maximum effect of a visual frame on the apparent body vertical was about 2 deg.

Brosgole and Cristal suggest the alternative view, that the rod and frame effect is a purely visual phenomenon and that any small postural effect is a result rather than the cause of the visual change. Of more immediate interest here is another experiment, in which they compared performance on the Witkin rod-and-frame test when the Ss were erect or supine and the task was to align the rod with the long axis of the body. They found mean effects of the frame of 7 and $9.7 \mathrm{deg}$ in the two conditions, and, although this difference is not significant, they seem to think that it requires an explanation. They say that the deterioration in the supine posture and in the tilted postures used by other workers is due not to the absence of gravitational cues or their conflict with visual ones, but simply to the fact that Ss are in an unfamiliar situation. They claim, without formal evidence, that the deterioration does not occur when $\mathbf{S}$ is standing and the display is on the floor or the ceiling, and they judge these situations to be familiar ones in which useful gravitational cues are lacking. This seems a very poor argument for the unimportance of postural cues, particularly in view of the equivocal results and the weakness of the concept of "unfamiliarity."

In line with the present reasoning, Wade (1970a) concludes that "the otolith system remains the major source of postural information contributing to visual orientation constancy." The otolith system does not induce error by adapting to prolonged head tilt, as shown by the fact that the aftereffect of such tilt is approximately the same whether the body is erect or supine (Day \& Wade, 1968). However, it seems surprising that the veridical information provided by the otoliths in the erect case should not have had the effect of actually decreasing the aftereffect due to adaptation of the neck system. (The means for the erect case are smaller, but not significantly.) Also surprising, on the same grounds, is Wade's (1970b) finding of a consistent effect of head tilt (E effect) with the body erect, but a small tendency in the opposite direction with the body supine.

In view of the uncertain results of these studies, the present experiment was designed to compare performance in the erect and supine postures and to study the relative susceptibility in the two postures to the common errors in visual orientation judgments-the effects of head tilt and of a tilted visual frame.

\section{METHOD}

\section{Apparatus}

The display visible to $S$ consisted simply of a pair of parallel 4.25-in. lines of light (the frame) in the frontal plane, with their centers at eye level and horizontally separated by 9 in. Midway between the frame lines, another line of light (the test line), 3.5 in. long, rotated in the frontal plane about its own center. These lines, which were mounted approximately 18 in. from S's eyes, consisted of $1 / 8$-in. slits milled in metal plates, the two plates carrying the frame slits being fastened to a partition in the rectangular wooden apparatus box and the circular plate carrying the test slit being free to rotate flush with the same partition. This circular plate protruded through the top of the box, where its angular position could be read off in half-degrees. $S$ viewed binocularly, with his face pressed against a rubber mask mounted in the end of the box. 
Table 1

Average Means (Upper Line) and Standard Deviations (Lower Line) in Degrees for All Groups and Conditions*

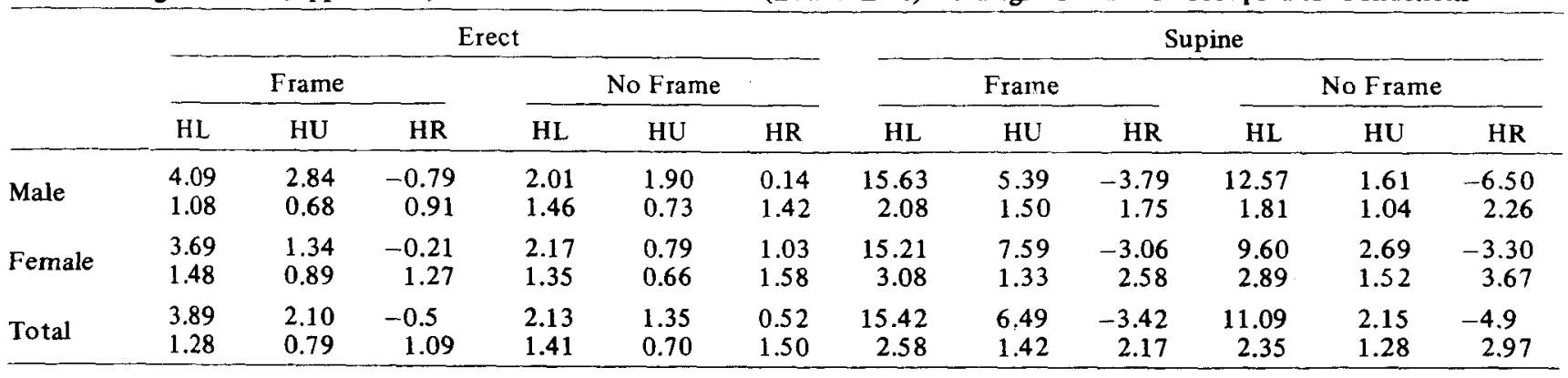

*Anticlockwise deviations are positive.

Using a small number of pilot $S$ s, the back-illumination of the slits was adjusted until (a) the frame slits appeared approximately half as bright as the test slit and (b) nothing else became visible inside the box during a period twice as long as a typical experimental session.

A chinrest and temple clamps maintained S's head in a constant relationship to the box as the latter was rotated in the frontoparallel plane. Either the right- or the left-hand bottom edge of the box could be lifted and a wooden block inserted to give the box an inclination of $20 \mathrm{deg}$. The whole box and block system stood on a platform which could be racked up or down to match the height of individual Ss when standing erect. In another condition, $S$ lay in a supine position on a mattress, with his body aligned by eye with parallel lines drawn on the floor. The box now stood on its front end and was lowered until the mask pressed on S's face and the chinrest/temple-clamp system could be secured. The frontoparallel rotation-now about a vertical axis-was achieved by means of stops fastened to the platform on which the box rested. In both erect and supine conditions, two bars pressed on S's shoulders and maintained them level, even when the head was tilted.

$E$ rotated the disk by hand, and the dangers inherent in this procedure were minimized by instructing $E$ not to watch the angular scale while the disk was in motion. $E$ developed a smooth rotation technique, in which one hand took over the work before the other hand reached the end of its transit. In any case, the large size of the disk relative to the target reduced any irregularities of motion.

The two parallel frame lines were fixed at $20 \mathrm{deg}$ counterclockwise relative to the sides of the box and therefore relative to S's head. Thus, when S's head was tilted to the right, the frame was parallel with his body axis, when S's head was upright on his body, the frame was 20 deg to the left, and when S's head was tilted to the left, the frame was 40 deg to the left relative to his body axis.

\section{Subjects}

Seven male and seven female Ss were used, ranging in age from 20 to 30 years. All Ss reported clear vision of the stimulus display with optical correction if normally used, and all Ss passed the Worchel test of standing on one leg for $5 \mathrm{sec}$ while blindfolded. Two candidates were rejected for failure on this test. No S had knowledge of the purpose of the experiment.

\section{Procedure}

Apart from the screening tests described above, no special preexperimental procedures or precautions were undertaken. The room lights, but not the display lights, were on while $S$ was positioned and secured. The instructions were as follows: "In this experiment, we are concerned with finding out how well you can set a line parallel to the midline of your body when you are standing up and when you are lying down. Sometimes the box to which your head is attached will be tilted a little and I want you to relax and let your head go along easily with the box and keep it in the final position of the box without straining. The three lines you saw before [in the screening test] will sometimes be there and sometimes only the center line. In any case, I want you to disregard the two outer lines and concentrate on the center one. On each trial it will start in a very tilted position and I shall move it back towards the upright. I want you to tell me as soon as it appears to be parallel to the midline of your body, that is, parallel to a line extending from a point midway between your shoulders to a point between your feet. When you tell me, I shall leave it on for a second or two and you can make further adjustments if you are not satisfied, but I must tell you that in this sort of task snap judgments are usually the best."

There were 12 conditions, since the frame could be either on or off $(F, N F), S$ could be either erect or supine ( $E, S)$, and his head could be either upright on his body or tilted left or right (HU, HL, HR). With only seven Ss of each sex, it was not possible completely to counterbalance the order of conditions, but there was an attempt to approximate this as closely as possible. Approximately half of each sex group (four males and three females) were given the six $E$ conditions first, the other half, the six S conditions. Approximately half of each resulting group (one or two $S$ s) were given NF before $F$ conditions in both $\mathrm{E}$ and $\mathrm{S}$ conditions, the other half, $\mathrm{F}$ before NF. Finally, each $\mathrm{S}$ was assigned an order of head tilt conditions which was the same for all four frame and posture conditions, so that each of the six possible orders of head tilt was used at least once and not more than twice. Preliminary scrutiny of the results in terms of condition order revealed negligible effects, and this factor was not included in the final analysis.

The conditions followed each other as rapidly as was allowed by the necessary alterations to the apparatus, and the whole experiment lasted about $1 \mathrm{~h}$. Each $\mathrm{S}$ made eight determinations under each of the 12 conditions, with the test line being initially positioned between 30 and 50 deg to the right on half the trials, and to the left on the other half.

\section{RESULTS}

The data for analysis consisted of the algebraic mean (constant error) and the standard deviation of the eight determinations made on each $\mathrm{S}$ under each condition. Table 1 shows these two measures averaged over the seven $\mathrm{Ss}$ in each sex group.

The mean and standard deviations were analyzed separately in two split-plot designs, with sex as a between-Ss factor and repeated measures on posture, head tilt, and frame. For each significant effect, a check 
was made that substitution of the degrees of freedom associated with the Geisser-Greenhouse conservative F test did not alter the significance level.

\section{Analysis of Standard Deviations}

It is clear that the presence or absence of the frame used in this experiment had no direct effect on the variability of settings. On the other hand, standard deviations are about $1 \mathrm{deg}$ larger in the supine than in the erect posture, the respective means being 2.13 and $1.14 \mathrm{deg}$, and this difference is highly significant $[F(1,12)=45.9, p<.001]$. Also highly significant $[F(2,24)=23.6, p<.001]$ is the difference of almost $1 \mathrm{deg}$ between head upright $(1.05 \mathrm{deg})$ and head tilted (1.91 and $1.92 \mathrm{deg}$ for HL and HR, respectively).

There is a tendency throughout for men to be less variable than women, but this is significant only when Ss are supine and deprived of visual frame when the difference is $1 \mathrm{deg}$. This accounts for a marginally significant Sex by Frame by Posture interaction $[F(1,12)=7.2, p<.05]$. No other effect is significant.

\section{Analysis of Constant Errors}

There is no significant difference in the constant error between the sexes either overall or in any individual condition. But the main effects of the three treatment variables are significant, as are all the two-way interactions among them, and so it is these interactions which must be interpreted. The most significant effect is the Head by Posture interaction $[F(2,24)=24.5$, $p<.001]$. Analysis of the simple main effects of head tilt for the two postures separately indicates that whereas, in the erect posture, there is a small nonsignificant tendency for judgments to follow head position (A effects of less than $2 \mathrm{deg}$ ), these effects reach highly significant values of 8.5 and $8.9 \mathrm{deg}$ when $\mathrm{S}$ is supine $[\mathrm{F}(2,48)=70, \mathrm{p}<.001]$.

The situation regarding the frame effect is similar. It will be recalled that the frame is always 20 deg to the left of the head position, and the overall tendency-apparent in Table 1-for settings to be more positive in frame than in nonframe conditions thus represents a tendency for $S$ to adopt the visual frame as his norm of uprightness. The Frame by Posture interaction is significant $[F(1,12)=8.2, p<.05]$ and analysis of the simple main effects shows that, whereas in the erect posture the frame effect is small and nonsignificant, when $S$ is supine it becomes a highly significant $3.4 \mathrm{deg}[F(1,24)=20, p<.001]$.

Finally, the Head by Frame interaction is significant $[F(2,24)=5.5, p<.05]$. Analysis of the simple main effects indicates, surprisingly, that the frame effect is significant with head left $[\mathrm{F}(1,36)=15.7, \mathrm{p}<.001]$ and with head upright $[F(1,36)=11, p<.01]$, but not with head right, i.e., when the frame is vertical. On the other hand, the effect of head tilt is significant with or without a frame $[F(2,48)=52$ and 30 , respectively, $\mathrm{p}<.001]$.

\section{DISCUSSION}

A few minor points will be disposed of first, before proceeding to the major findings. Witkin (1949) introduced the concept of field dependency as a basic personality variable, the original purpose of which was to account for the large individual differences in the frame effect. He claimed specifically that women were more field-dependent than men, which meant that they were less able to make use of postural information to counter the influence of a misleading visual frame, and were more disoriented by head tilt. Sandström (1956), on the other hand, found no sex differences in the effect of head tilt on apparent visual verticality. The present results clearly support Sandström, there being no sex differences in constant error, due either to head or frame orientation, although female variability tended to be greater throughout, and significantly so in the supine position with no visual frame.

In the basic control condition (erect, no frame, head upright), the average standard deviation of $0.7 \mathrm{deg}$ is probably comparable with earlier investigators' variability measures of $1 \mathrm{deg}$, or a little more, since they typically used average unsigned deviations from the objective vertical, which include constant as well as variable error.

Cohen and Tepas (1958) reported a mean control constant error of $2.3 \mathrm{deg}$ anticlockwise, but such observations should be treated with skepticism, since they can be so easily induced by slight irregularities of apparatus or S's posture. In the present study, control constant errors ranged from 0 up to $3.3 \mathrm{deg}$ anticlockwise, while Gibson and Radner's (1937) ranged up to 2 deg in either direction.

The increase in variability with head tilt confirms earlier findings (e.g., Mann, Berthelot-Berry, \& Dauterive, 1949). On the other hand, Neal's (1926) report that the presence of a visual frame does not affect consistency was also confirmed, though presumably this applies only to relatively unstructured frames.

Finally, there are no clear implications concerning the old controversy about the relative magnitudes of frameand head-tilt effects, since this issue has usually been discussed in the context of available gravitational cues and, under these conditions, neither of the effects was significant in the present study. It can be reported only that in the supine condition, the frame effect averaged about $3.5 \mathrm{deg}$, while the average $\mathrm{A}$ effect was about $8.5 \mathrm{deg}$. But, without some way of comparing the independent variables, any conclusion based on this difference would seem pointless.

The major finding of the study, however, is that, although the data show a small frame effect and $A$ effect in the erect posture, these are not significant, whereas the corresponding effects for supine Ss are large and 
highly significant. This effect of loss of direct gravitational information is also reflected in the standard-deviation data. This is therefore the first report of a case in which both of the common sources of error in verticality judgment-frame effects and head-tilt effect-have been found to be significant only in the absence of relevant gravitational cues. This pattern is shown clearly in Fig. 1, in which constant errors are shown separately for erect and supine conditions, the conditions being ordered along the abscissa according to the location of the means of their supine versions. The dramatic suppression of constant error in the erect conditions is clearly evident. The figure also shows the fairly consistent doubling of standard deviations, which is caused by loss of gravitational cues.

The predominance of the $A$ effect in the present study-in the supine posture only 2 of the 14 Ss produced an $E$ effect in one of the four conditions-appears to add confusion to the problem of specifying the conditions under which the two effects occur, since it contradicts the notion that $\mathrm{E}$ effects are

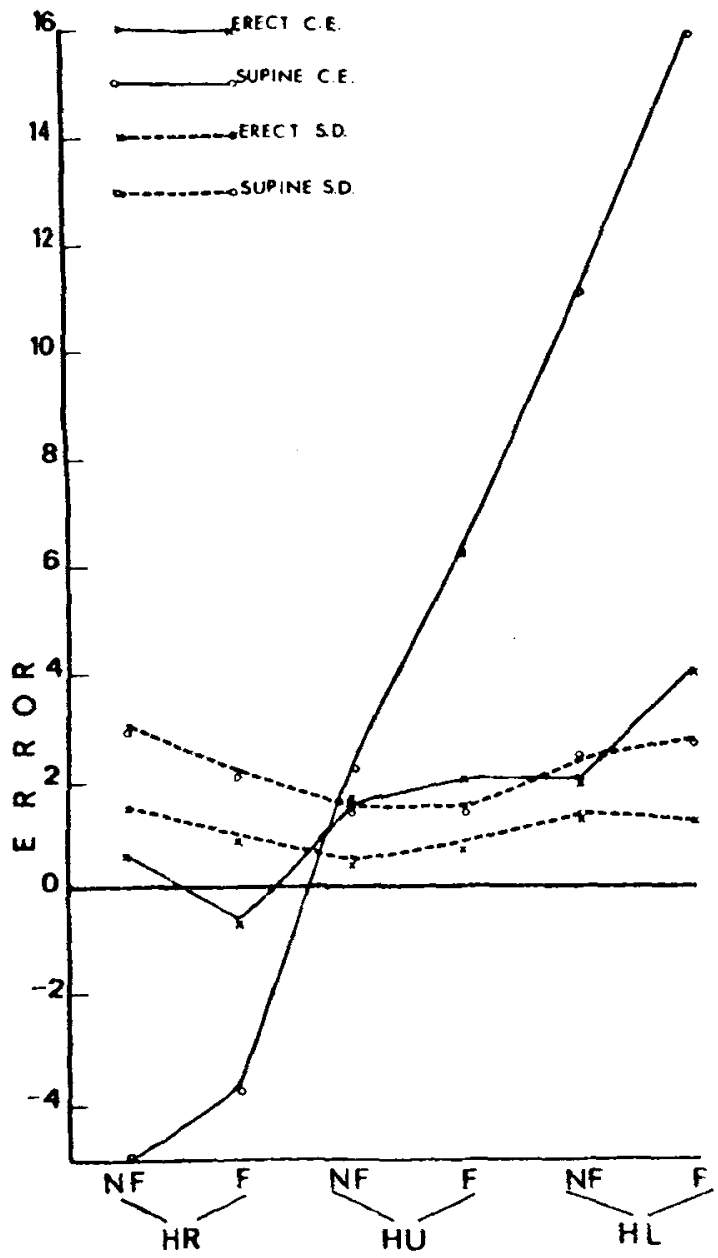

Fig. 1. Constant errors and mean intra-S standard deviations for erect and supine conditions (in degrees, positive indicates anticlockwise constant errors).

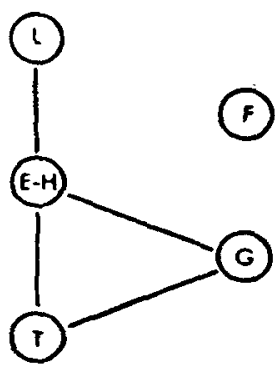

2 EREST - FRAME

3 SUPINE - NO FRAME
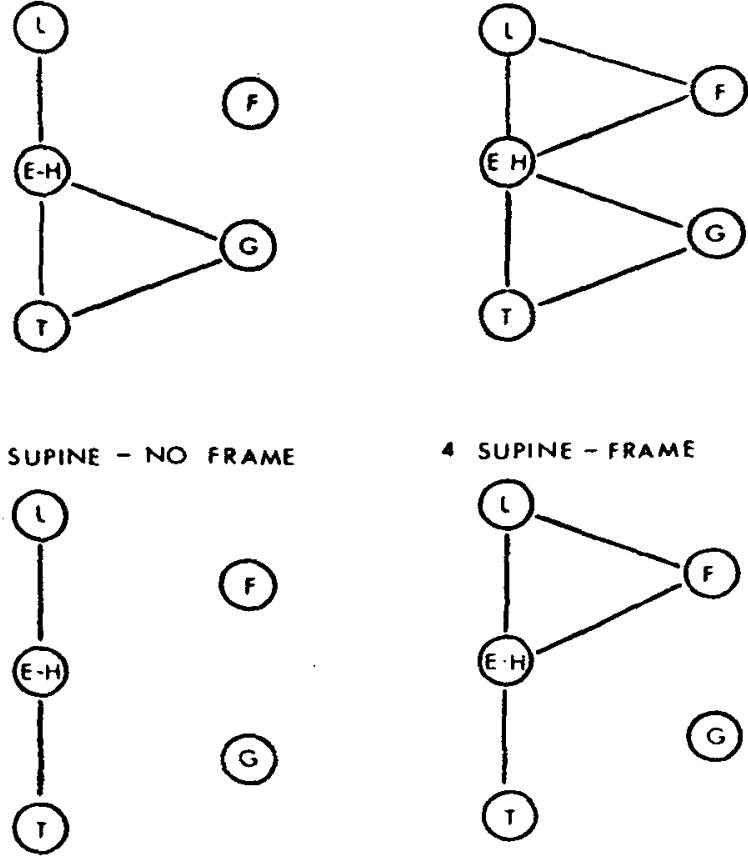

Fig. 2. Relationships about which information is potentially available to $S$ are indicated by linking lines. The elements are the visual stimulus line (L), the eye-head system (E-H), the trunk (T), the visual frame (F), and the direction of gravity (G).

associated with head tilt and small degrees of body tilt. The present experiment used a head tilt within $8 \mathrm{deg}$ of that found by Witkin and Asch (1948) to give a maximal E effect! On the other hand, it is consistent with the theory presented here, that the absence of gravitational cues in the supine posture should lead to underconstancy (the A effect). Day and Wade (1969) review evidence that labyrinthine-defectives similarly show the A effect in conditions where normal Ss show the $\mathrm{E}$ effect.

Figure 2 shows a schematic representation of the major factors involved in the various conditions. In order to carry out the task of relating line orientation to trunk orientation, the system must presumably have information about the relationship of the line to the eye-head complex and about the relationship of the latter to the trunk. In the erect conditions, information is potentially available about the relationship of gravity to both head and trunk separately, thus augmenting the information about their mutual relationship and so reducing error. In the frame conditions, the frame can be visually related to both the line and the eye-head system. It is possible that the first of these relationships is critical for the frame effect, i.e., it is purely visual, as suggested by Brosgole and Cristal. But this would not explain the large difference between erect and supine conditions in the size of the effect. It seems more likely that, in sighted people, part of the postural control system depends on a more or less continuous monitoring 
of the relationship between eye-head and a normally vertical-horizontal visual frame. (Evidence for a similar system of control for the straight-ahead resting position of the eyes has been reported by Craske \& Templeton, 1968.) The information from a misleading visual frame will thus combine with the veridical kinesthetic information to produce a faulty apparent orientation of head on trunk, except when the kinesthetic information is supported by gravitational cues to head orientation. This assumed effect of visual-frame tilt on apparent head orientation has never been adequately tested. But Passey (1950) reported an effect of a visual frame on apparent body orientation with a maximum of about $2 \mathrm{deg}$, so it seems possible that a corresonding head effect might be an important factor in the frame effects of about $3.5 \mathrm{deg}$ found in the present study.

In this analysis, eye and head have been combined into a single element as though the relationship between them was fixed. This is not the case, particularly when the head is tilted, as attested by the eye-torsion literature, e.g., Miller (1962). The effect of eye torsion should be in the direction of the $E$ effect or presumably a reduction in the size of the $A$ effect (Howard \& Templeton, 1966, p. 193). Since residual eye torsion with the head stationary in a tilted position is probably a utricular effect (Howard \& Templeton, 1966, p. 54), this is another possible mechanism whereby gravitational factors reduce the effect of head tilt in the erect conditions. The problem about this interpretation is that if a situation could be devised similar to the present one, but yielding predominantly $\mathrm{E}$ effects, then it would have to be predicted that eye torsion would act to increase the effect of head tilt in the erect conditions.

This study does not directly indicate the nature of the gravitational cues which maintain constancy, but vestibular input is likely to be important in view of the parallel suppression of the head-tilt effect in normals compared with labyrinthine-defectives reported by Miller and Graybiel (1966). If this is true, then it is further evidence against the views either that the vestibular system is vestigial or that it is subject to characteristic errors which are responsible for the effects of head tilt on verticality judgments. The relatively small long-term effects of vestibular loss on general posture control may indicate only that other cues can take over the functions normally performed by the vestibular system.

The fact that the error effects are not only reduced in the erect posture, but reduced to statistical insignificance is probably related to the small amount of head and body support afforded by the apparatus-the same explanation as was suggested for Clark and Graybiel's (1968) failure to find any A or E effect in labyrinthine-defective or normal Ss.

\section{REFERENCES}

Barany, R. Zur Klinik und Theorie des Eisenbahn-Nystagmus. Archiv für Augenheilkunde, 1921, 87, 139-142.
Brosgole, L., \& Cristal, R. M. The role of phenomenal displacement on the perception of the visual upright. Perception \& Psychophysics. 1967, 2, 179-188.

Clark, B., \& Graybiel, A. Contributing factors in the perception of the oculogravic illusion. American Journal of Psychology. $1963,76,18-27$.

Clark, B., \& Graybiel, A. Egocentric visual localization in normals and partially blind during exposure to centripetal force. American Journal of Psychology, 1968, 81, 314-318.

Cohen, W., \& Tepas, D. Temporal factors in the perception of verticality. American Journal of Psychology, 1958, 71, $760-763$.

Craske, B., \& Templeton, W. B. Prolonged oscillation of the eyes induced by conflicting position input. Journal of Experimental Psychology, 1968, 76, 387-393.

Day, R. H., \& Wade, N. S. Visual spatial aftereffect from prolonged head tilt. Science, 1966, 154, 1201-1202.

Day, R. H., \& Wade, N. S. Involvement of neck proprioceptive system in visual aftereffect from prolonged head tilt. Quarterly Journal of Experimental Psychology, 1968, 20, $290-293$.

Day, R. H., \& Wade, N. J. Mechanisms involved in visual orientation constancy. Psychological Bulletin, 1969, 71, 33-42.

Feilchenfeld, H. Zur Lageschatzung bei seitlichen Kopfneigungen. Zeitschrift für Psychologische und Physiologische Sinnesorgane, 1903, 31, 127-150.

Fischer, M. H. Messende Untersuchungen uber die Gegenrollung der Augen und die Lokalization der scheinbaren Vertikalen bei seitlicher Neigung des Gesamtkorpers bis $\mathrm{zu} 360^{\circ}:$ II Mitteilung. Untersuchungen an normalen. v. Graefes Archiv fur Ophthalmologie, 1930, 123, 476-508.

Gibson, J. J., \& Radner, M. Adaptation, aftereffect, and contrast in the perception of tilted lines. I. Quantitative studies. Journal of Experimental Psychology, 1937, 20, 453-467

Howard, I. P., \& Templeton, W. B. Human spatial orientation. London: Wiley, 1966.

Kleint, H. Versuche über die Wahrnehmung. Zeitschrift für Psychologie, 1936, 138, 1-34.

Mann, C. W., Berthelot-Berry, N., \& Dauterive, H. J. The perception of the vertical: I. Visual and non-labyrinthine cues. Journal of Experimental Psychology, 1949, 39, 538-547.

Miller, E. F. Counter-rolling of the human eyes produced by head tilt with respect to gravity. Acta Otolaryngologica, Stockholm, 1962, 54, 479-501.

Miller, E. F., Fregly, A. R., van den Brink, G., \& Graybiel. A. Egocentric visual localization of the horizontal as a function of lateral body tilt up to $\pm 90^{\circ}$ from gravitational vertical. NSAM-942, NASA Order R-47, Naval School of Aviation Medicine, Pensacola, Florida, 1965.

Miller, E. F., \& Graybiel, A. Role of otolith organs in the perception of horizontality. American Journal of Psychology, $1966,79,24-37$.

Neal, E. Visual localization of the vertical. American Journal of Psychology, 1926, 37, 287-291.

Passey, G. E. The perception of the vertical: IX. Adjustment of the visual vertical from various magnitudes of body tilt. Internal Report No.15, U.S. Naval School of Aviation Medical Research and Tulane University, 1950.

Rock, I. The perception of the egocentric orientation of a line. Journal of Experimental Psychology, 1954, 48, 367-374.

Sandström, C. I. Sex differences in tactile-kinaesthetic and visual perception of verticality. Quarterly Journal of Experimental Psychology, 1956, 8, 1-7.

Thetford, P. E., \& Guedry, F. E. The postural vertical in unilaterally labyrinthect omized individuals. Project No. NM.001.063.01.26, Joint Report No. 26, U.S. Naval School of Aviation Medicine, Pensacola, Florida, 1952a.

Thetford, P. E., \& Guedry, F. E. Judgment of the postural vertical during exposure to a misleading visual framework in unilaterally labyrinthectomized subjects. Project 
No. NM.001.063.01.27, Joint Report No. 27, U.S. Naval School of Aviation Medicine, Pensacola, Florida, $1952 \mathrm{~b}$.

Wade, N. S. Effect of prolonged tilt on visual orientation. Quarterly Journal of Experimental Psychology, 1970a, 22, 423-439.

Wade, N. S. Visual orientation during lateral head tilt when upright and supine. Quarterly Journal of Experimental Psychology, 1970b, 22, 420-422.

Wertheimer, M. Experimentelle Studien über das Sehen von Bewegung. Zeitschrift für Psychologische und Physiologische Sinnesorgane, 1912, 61, 161-265.

Wing, M. E. The response of the otolith organs to tilt. Acta
Laryngologica, Stockholm, 1963, 56, 537-545.

Witkin, H. A. The nature and importance of individual differences in perception. Journal of Personality, 1949, 18, 145-170.

Witkin, H. A., \& Asch, S. E. Studies in space orientation: IV. Further experiments on perception of the upright with displaced visual fields. Journal of Experimental Psychology, $1948,38,762-782$.

(Received for publication April 6, 1973; revision received June $18,1973$. ) 